\title{
A DIVERSIDADE NA EDUCAÇÃO ESCOLAR: O CURRÍCULO COMO ARTEFATO CULTURAL
}

\section{DIVERSITY IN SCHOOL EDUCATION: CURRICULUM AS CULTURAL ARTIFACT}

\author{
FELIPE, Delton Aparecido \\ ddelton@gmail.com \\ Universidade do Estado do Paraná (Unespar/Campo Mourão) \\ FRANÇA, Fabiane Freire \\ prof.fabianefreire@gmail.com \\ Universidade do Estado do Paraná (Unespar/Campo Mourão)
}

\begin{abstract}
RESUMO O presente artigo tem como objetivo compreender a contribuição das discussões sobre diversidade cultural à ação docente no que diz respeito à educação escolar. Ressalta-se a necessidade de formulação de subsídios teóricos e metodológicos à formação docente no sentido de pensar uma prática pedagógica crítica e problematizadora das diversas culturas. Nesse sentido, questiona-se: como trabalhar a diversidade cultural em sala de aula, com o propósito de valorizar as múltiplas identidades constituintes no ambiente escolar? Para responder a esta questão utiliza-se neste artigo, como soma de lentes, as teorias curriculares críticas e os Estudos Culturais, que têm sido palco para debates proeminentes em torno do significado da cultura, da reprodução e produção de identidades. No final do século XIX e início do século $X X$, predominavam as ideias de superioridade de uma raça sobre a outra e também do gênero masculino sobre o feminino que determinavam o currículo da educação de mulheres e negros, considerados biologicamente inferiores em nível intelectual, o que historicamente justificou a educação diferenciada para mulheres e para a população negra. Os temas sobre gênero e sexualidade, raça e etnia, colonial e pós-colonial, pelo viés das teorias curriculares críticas, são discutidos no bojo das relações de poder entre os sujeitos e entre os grupos culturais. No decorrer do texto são apresentadas algumas das teorias curriculares críticas e o papel do currículo escolar como uma construção social e cultural. Estas fontes evidenciam que a educação escolar pode contribuir para a confirmação e/ou contestação de estereótipos relacionados a grupos menos favorecidos socialmente, dentre eles, negros e mulheres. Em vista disso, conclui-se que trabalhar na perspectiva da diversidade cultural, na educação escolar por meio do currículo significa efetivar uma pedagogia com propostas a uma formação docente que problematize as práticas cotidianas.
\end{abstract}


PALAVRAS-CHAVE: Educação. Formação Docente. Diversidade. Currículo.

ABSTRACT This article aims to understand the contribution of the discussions on cultural diversity in the teacher's activities with regard to school education. We stress the need to formulate theoretical and methodological teacher training towards a pedagogical practice critical thinking and problem of different cultures. In this sense, the question is: how to work the cultural diversity in the classroom, in order to appreciate the multiple identities constituents in the school environment? To answer this question, we used the sum of the lens critical curriculum theory and cultural studies as we believe that has been prominent on stage for debates about the meaning of culture, breeding and production of identities. In the late nineteenth and early twentieth century, dominated the ideas of superiority of one race over another and the male over female who determined the curriculum of education of women and blacks, considered biologically inferior in intellectual level, which historically justified the differentiated education for women and black people. Issues of gender and sexuality, race and ethnicity, colonial and post-colonial, from the perspective of critical theory curriculum, are discussed in the midst of power relations among individuals and between cultural groups. Throughout the text are some of the critical curriculum theories and the role of the school curriculum as a social and cultural construction. These sources show that school education can contribute to the confirmation and / or challenge stereotypes relating socially disadvantaged groups, including blacks and women. As a result, it is concluded that working from the perspective of cultural diversity in school education through the curriculum means an effective pedagogy of a teacher training proposals that problematize the everyday practices.

KEYWORDS: Education. Teacher Education. Diversity. Curriculum

\section{INTRODUÇÃO}

As histórias individuais são marcadas pela eliminação simbólica e/ou física do "outro". Os processos de negação desses "outros", na maioria das vezes, ocorreram no plano das representações e do imaginário social quando são estabelecidos os conceitos do que é ser belo, do que ser homem, do que é ser mulher, ou do que é ser brasileiro.

Ao tratar a questão da diversidade cultural, Abramowicz (2006) afirma que todo o brasileiro vive uma situação no mínimo, inusitada. De um lado, há o discurso de que o brasileiro é um povo único, fruto de um intenso processo de miscigenação e mestiçagem, que gerou uma nação singular com indivíduos culturalmente diversificados. De outro, são vivenciadas nas relações cotidianas inúmeras práticas preconceituosas, discriminatórias e racistas em relação a alguns segmentos da 
população, como as mulheres, os indígenas, os afrodescendentes e as pessoas com deficiência.

$\mathrm{Na}$ atualidade, mesmo com manutenção de vários padrões de comportamento discriminatórios no âmbito escolar, os documentos relacionados à educação brasileira outorgam que o país é construído tendo por base a diversidade cultural. Mas o que significa diversidade cultural em um país onde os diversos grupos sociais são marginalizados em suas representações?

Os estudos de Silva (2005) mostram que apesar do discurso da diversidade cultural registrados nos documentos oficiais, visto que os bancos escolares são frequentados por alunos de diferentes pertencimentos étnico-raciais e gênero, os conteúdos programáticos dos livros didáticos e dos currículos escolares apresentam ainda o homem branco e heterossexual como padrão.

No intuito de refletir sobre as possibilidades de ação pedagógica para tratar da diversidade cultural na educação escolar, questiona-se: como trabalhar a diversidade cultural em sala de aula, com o propósito de valorizar as múltiplas identidades constituintes no ambiente escolar?

Silva (2005) afirma que, nos livros didáticos, nos currículos escolares e nas falas dos professores, ainda há uma invisibilidade ou uma visibilidade subalterna de diversos grupos sociais, como os negros, os indígenas, as mulheres e as pessoas com necessidades especiais que geralmente são considerados os "outros" na sociedade. O preconceito instituído e manifestado na prática pedagógica pode levar tais grupos a uma autorrejeição e rejeição ao seu grupo social, comprometendo os processos constitutivos de suas identidades.

Refletindo sobre essas questões, objetiva-se ainda compreender o papel do currículo escolar como uma construção social e cultural, envolvido por relações de poder. Para tanto, a discussão baseia-se no currículo como artefato cultural para uma melhor reflexão sobre a concepção de diversidade escolar na atualidade em direção a uma análise dinâmica e crítica sobre a ação docente.

\section{QUE É DIVERSIDADE CULTURAL?}


Para Abramowicz (2006, p.12), "diversidade pode significar variedade, diferença e multiplicidade. A diferença é qualidade do que é diferente; o que distingue uma coisa de outra, a falta de igualdade ou de semelhança". Nesse sentido, é possível afirmar que onde há diversidade existe diferença.

Costa (2008) afirma que a diferença não é uma marca do sujeito, mas sim uma marca que o constitui socialmente, e se estabeleceu como uma forma de exclusão. Ser diferente na educação ainda significa ser excluído e/ou ser subrepresentado nas instâncias sociais.

Reconhecer a diferença para estabelecer a existência de uma diversidade cultural no Brasil não é suficiente para combater os estereótipos e os estigmas, que ainda marginalizam pessoas nas escolas e na sociedade. Maria Vera Candau (2005, p.19) afirma que:

Não se deve contrapor igualdade a diferença. De fato, a igualdade não está oposta à diferença, e sim à desigualdade, e diferença não se opõe à igualdade, e sim à padronização, à produção em série, à uniformidade, a sempre o "mesmo", à mesmice.

Reconhecer a diferença é questionar os conceitos homogêneos, estáveis e permanentes que excluem o diferente de certo padrão estabelecido socialmente. Dessa maneira, trabalhar em uma perspectiva do currículo enquanto artefato cultural demanda que as certezas que foram socialmente construídas sejam fragilizadas e desvanecidas. Para tanto, é preciso desconstruir, pluralizar, ressignificar, reinventar identidades e subjetividades, saberes, valores, convicções, horizonte de sentidos. Somos obrigados a assumir o múltiplo, o plural, o diferente, o híbrido, na sociedade como um todo (CANDAU, 2005).

Falar sobre diversidade não pode ser só um exercício de perceber os diferentes, de tolerar o "outro". Antes de tolerar, respeitar e admitir a diferença é preciso explicar como essa diferença é produzida e quais são jogos de poder estabelecidos por ela. Como alerta Silva (2000), a diversidade biológica pode ser um produto da natureza, mas o mesmo não se pode dizer sobre a diversidade cultural, pois, de acordo com autor, a diversidade cultural não é um ponto de origem, mas sim um processo conduzido pelas relações de poder, constitutivo da sociedade que 
estabelece o "outro" diferente do "eu" e o "eu" diferente do "outro" como uma forma de exclusão e marginalização.

Uma ação pedagógica pautada na diversidade cultural tem como princípio uma política curricular da identidade e da diferença. Com a obrigação de ir além das benevolentes declarações de boa vontade para com a diferença, ela coloca em seu centro uma teoria que permita não só reconhecer e celebrar a diferença, mas também questioná-la, a fim de perceber como está discursivamente constituída.

É parte deste fundamento a afirmação de que os conceitos compõem parte do estabelecimento de uma determinada cultura ${ }^{1}$, uma vez que os indivíduos se comportam e se constroem de acordo com os significados que circulam em determinado tempo e espaço social. Os discursos, dependendo de quem os emite, acabam por justificar e fornecer legitimidade às desigualdades de classe, de gênero, de etnia, de raça, de sexualidade.

Todavia, os conceitos considerados legítimos podem vir a ser contestados e sofrer um questionamento radical de sua "naturalidade", acentuada pelas instituições sociais. O movimento das mulheres negras é um exemplo de desencadeamento de rupturas importantes dentro do feminismo, uma contestação do pensamento hegemônico sobre a mulher. Com os questionamentos das mulheres lésbicas, os debates feministas tornaram-se ainda mais acirrados, possibilitando a definição de reivindicações ao conjunto das mulheres.

Assim, a organização curricular constitui-se como um instrumento relevante no processo de reconhecimento e trabalho com a diversidade cultural em sala de aula. Silva (2000, p. 82) afirma que entender o currículo como artefato cultural demanda entender que a articulação poder-saber reflete na condição não neutra de todo e qualquer conceito. Dessa articulação emergem categorias, como indivíduos "bons e maus", "normais e anormais", "melhores e piores", dentre outras que implicam operações de inclusão e exclusão social.

Dessa forma, Silva (2000) entende ser necessária a rejeição das oposições duais entre conceitos. Por conseguinte, questionar as categorias conceituais tidas

\footnotetext{
${ }^{1}$ Nesta perspectiva entende-se cultura como um campo de luta e contestação, em que se produzem tanto os sentidos quanto os sujeitos que constituem os diferentes grupos sociais em sua singularidade.
} 
como verdades permanentes significa realizar um processo de "desconstrução", "problematização" da "verdade" a partir de seu caráter histórico-social e sua articulação com a produção e circulação do poder. Desconstruir os conceitos padrões do que é dito "normal" faz-se necessário.

Desconstruir significa contrariar a lógica da polaridade e da dicotomia entre o diferente e o normal, pois sua oposição é produzida e não natural. Desconstruir implica em buscar na história a construção da polaridade, a hierarquia do "normal" e as posturas preconceituosas. Nessa linha de pensamento, analisar qualquer conceito corresponde a compreendê-lo como uma representação provisória construída por jogos de poder.

Louro (1997) destaca que as representações de quem somos e o que somos são produzidas e criadas por relações de poder, uma vez que a maneira como um grupo social se representa ou é representado indica o quanto exerce poder e pode dizer quem é o "outro", o considerado "diferente" do padrão. As representações sociais seriam, portanto, um dos processos que constroem a diferenciação, que, todavia, está em constante movimento. Uma sociedade cujo poder é descentrado interfere na estruturação da identidade, que passa a se constituir mediante uma noção provisória: uma identidade mutável, que varia de acordo como o sujeito é representado socialmente.

Pode-se compreender a constituição das identidades dos sujeitos sociais como um dos produtos das relações entre os indivíduos e, nesse sentido, a identidade do "normal" e do "diferente" se distingue por aquilo que eles/elas não são. A discussão sobre identidade centra-se na tensão entre o essencialismo - que se fundamenta na história e na biologia - e o não essencialismo - que questiona as concepções fixas e permanentes.

A definição da identidade de um indivíduo do ponto de vista do gênero, da etnia, da religião, da nação a que pertence depende de um conjunto de afirmações e negações.

A afirmação "sou brasileiro", na verdade, é parte de uma extensa cadeia de "negações", de expressões negativas de identidade, de diferenças. Por trás das afirmações "sou brasileiro" deve-se ler: "não sou argentino", "não sou chinês", "não sou japonês" e assim por diante, numa cadeia, neste caso, quase interminável. (SILVA, 2000, p. 75). 
Para Woodward (2007) e Silva (2000), a representação é compreendida como um processo cultural que estabelece os sistemas simbólicos que definem as identidades individuais e coletivas. Essas representações explicam o que o sujeito é, o que poderia ser, o que ele quer ser, assim como os lugares e as posições de onde pode falar.

Percorrendo essa mesma trajetória teórica, Louro (1997) explica as representações de professores e professoras como conceitos que descrevem seus modos, suas práticas, o que pode ou não fazer. Como qualquer outro grupo social, educadores são objeto de representações que, no percurso histórico, prescrevem as identidades marcadas por características produzidas por efeitos de poder. $\mathrm{Na}$ instituição escolar, por exemplo, a ação pedagógica impõe significações de determinado grupo ou classe social como cultura "legítima", dissimulando as relações de poder que as sustentam.

Para Silva (2000, p. 73 ), os discursos educacionais mais recentes trazem como marca a perspectiva da diversidade, embora, neste processo, a diferença e a identidade tendam a ser naturalizadas, cristalizadas, essencializadas. Essa posição é pautada no respeito e na tolerância à diversidade e à diferença entre os indivíduos com o intuito de amenizar os embates políticos e culturais e produzir a ilusão de levar em conta as transformações sociais.

Onde existe diferença, existe poder, que inclui e exclui indivíduos ou grupos, que classifica, que normaliza, que hierarquiza e fixa uma determinada identidade como referência por meio da qual outras identidades são avaliadas. Silva (2000) e Woodward (2007) focalizam a diferença como construções sociais e culturais e, portanto, representação do "que eu sou" e do "que o outro é".

A representação inclui as práticas de significação e os sistemas simbólicos por meio dos quais os significados são produzidos, posicionando-nos como sujeito. É por meio dos significados produzidos pelas representações que damos sentido à nossa experiência e àquilo que somos. Podemos inclusive sugerir que esses sistemas simbólicos tornam possível aquilo que somos e aquilo no qual podemos nos tornar (WOODWARD, 2007, p. 17).

Identidade e diferença, enquanto sistemas de significação e, portanto, signos, carregam o traço daquilo que substituem e daquilo que não são, ou seja, da 
diferença. Silva (2000) defende que isso condiciona a identidade e a diferença entre homens e mulheres como significados sociais e históricos e, por consequência, incertos e vacilantes.

A identidade, tal como a diferença, é uma relação social. Isso significa que sua definição - discursiva e linguística - está sujeita a vetores de força, a relações de poder. Elas não são definidas, elas são impostas. Elas não convivem harmoniosamente, lado a lado, em um campo de hierarquias; elas são disputadas (SILVA, 2000, p. 81).

Como afirma Costa (2008), identidade e diferença são inseparáveis, dependendo uma da outra. Elas são produzidas na trama da linguagem; a identidade e a diferença são construídas no discurso, por isso é necessário compreender o modo como são produzidas nas instituições e na história por meio dos discursos.

Nesse sentido, Foucault (2002, p.21) argumenta que:

[...] são os discursos eles mesmos que exercem seu próprio controle; procedimentos que funcionam, sobretudo, a título de princípios de classificação, de ordenação, de distribuição, como se tratasse desta vez, de submeter outra dimensão do discurso: a do acontecimento e do acaso.

O discurso, por meio da afirmação de conceitos essencialistas, não faz transparecer os processos de mudanças e de transformações sociais que padronizam e marginalizam os diversos grupos sociais. Para Hall (2000), os conceitos devem ser questionados a fim de se perceber como são construídos, em uma prática discursiva que se envolve nas relações assimétricas de poder.

Os professores e as professoras que percebem em sua ação pedagógica como os conceitos de gênero, raça e etnia são socialmente construídos e discursivamente usados para marginalizar o "outro" poderão contribuir para a constituição de uma diversidade cultural que não seja apenas tolerante, mas que perceba que o "eu" e o "outro" têm os mesmos direitos e devem ter a mesma representatividade, tanto nos conteúdos escolares quanto nas instituições sociais.

\section{PENSAR A DIVERSIDADE EM SALA DE AULA}


Para problematizar as possibilidades de uma formação de docentes que tenha como eixo norteador a educação pautada na diversidade, este artigo utiliza as contribuições teóricas do currículo como artefato cultural. Os argumentos foram construídos de modo a defender a relação entre currículo e cultura, e a ambos como práticas de significação, produção, relação social, relação de poder e práticas que produzem e reproduzem identidades sociais.

A percepção do currículo como artefato cultural permite retirar os conceitos da "caixa fechada"; isso significa que os conceitos passam a ser vistos como constituídos socialmente. Os conhecimentos corporificados no currículo, sua distribuição e seleção são diretamente mediados e controlados pelos ditames da cultura preponderante na sociedade. Assim, a cultura não só influencia a maneira como os conhecimentos são selecionados, como ela própria é elemento de seleção.

Nessa perspectiva, a cultura não é venerada, porque isso tiraria a sua constituição social e retiraria o poder que, inevitavelmente, está em suas mãos; poder de explicar e coordenar as relações sociais e em fazer seleções do que é válido e aceito e do que é inútil e irrelevante. "A cultura organiza valores e significados da sociedade, mas também institui outros valores e significados ao fazer isto. Por isso é necessário considerar as suas condições de produção e as relações com o mundo que produz". (ARAÚJO, 2004, p. 6).

Nessa dimensão, as escolas com seus currículos não apenas reproduzem conhecimentos neutros, dado que seus tentáculos aderem-se a um processo de conhecimento que é constituído de "negociações intersubjetivas conflitivas". Assim, ao selecionarem os conhecimentos que deverão ser ensinados aos alunos, "as escolas fazem mais do que intermediar saberes ou constituir espaço único de internalização de valores e normas", porque os sujeitos não são apenas receptores ou reprodutores, podem ser, também, "[...] criadores de significados em relações socialmente construídas”. (SILVA, 2000, p. 113).

Para Apple (1999) reconhecer no currículo questões que sempre estiveram ligadas aos conflitos de classe, raça, gênero, sexo e religião, no contexto histórico de diversos países, faz ressaltar outras questões. Como é o caso da definição de um conhecimento universal considerado digno em relação aos outros, pois há uma 
seleção constituída no currículo que deriva de interesses das classes e grupos dominantes.

\begin{abstract}
Foucault lembrou-nos de que, se quisermos compreender como funciona o poder, basta que olhemos para as margens, basta que observemos os conhecimentos, autocompreensão e a luta daqueles que foram relegados à condição de "os outros" por poderosos grupos dessa sociedade [...] pessoas de cor, mulheres que se recusam a aceitar o controle alheio sobre suas vidas e corpos, gays e lésbicas, os pobres e, bem sei por minha própria experiência a vibrante cultura da classe trabalhadora. É a partir do conhecimento dessas diferenças que o diálogo do currículo pode prosseguir. (APPLE, 1999, p. 77).
\end{abstract}

Os aspectos do currículo devem ser analisados como um todo, pois por um lado há um "currículo oficial" que deixa explícito qual conteúdo deve ser trabalhado no ambiente escolar, por outro lado, deve-se considerar também o que está implícito nesse processo, as normas e valores que são transmitidos de forma oculta. Embora esse processo não faça parte do currículo oficial, se faz presente na discussão e no ambiente escolar.

Silva (2001) afirma que, na perspectiva crítica, currículo oculto são atitudes, valores e comportamentos. Pode-se considerar também o conformismo, a obediência, bem como as relações de gênero, sexualidade, raça, etnia. Como consequência desse processo, crianças e adolescentes das classes menos favorecidas são educadas para serem subordinadas, enquanto aos pertencentes às classes hegemônicas se ensina a função de dominação.

Silva (2001) enfatiza a necessidade de o currículo questionar não apenas "o quê?", mas "por quê?" ensinar determinados conhecimentos, pois a produção sobre currículo vai além de uma seleção de conteúdos, sendo esse currículo um produtor de identidades. "As teorias críticas e pós-críticas de currículo estão preocupadas com as conexões entre saber, identidade e poder". (SILVA, 2001, p.16).

Em consonância com esse eixo explicativo, a cultura é uma experiência humana e é considerada construções e interpretações que não são únicas e verdadeiras, mas subjetivas, relativas e políticas. O conhecimento é uma destas construções, pois não é neutro, nem homogêneo e nem estático. Por isso, o conhecimento é visto como uma categoria permeada por relações históricas, sociais e políticas, constitui-se de valores, significados e sentidos múltiplos. Ou seja, o 
conhecimento expressa visões particulares, significados próprios de determinadas culturas e insere-se na disputa pela manutenção do poder.

Nessa discussão, não se pode esquecer que a identidade, tal como a diferença, é uma relação social. Isso significa que sua definição - discursiva e linguística - está sujeita a vetores de força e relações de poder. Elas não são simplesmente definidas, são impostas. Silva (2000, p.81) salienta que "a identidade e a diferença não são, nunca, inocentes", e onde existe diferenciação, aí está presente o poder.

Silva (2000) destaca, no entanto, que há uma série de processos que traduzem essa diferenciação, como incluir e excluir, identificando e representando, marcando, simbolizando quem pertence e quem não pertence; ou também demarcar fronteiras, que definam e separem "nós" e "eles", classificando e normalizando.

De acordo com Gusmão (1999), quando se tem como objetivo na educação, assimilar o indivíduo à ordem social, integrando-o e diferenciando-o por suas características pessoais, por gênero e por idade, procura-se garantir aí o equilíbrio da vida em sociedade. "A educação realiza-se, então, no interior da sociedade, composta por diferentes grupos e culturas, visando certo controle sobre a existência social, de modo a assegurar sua reprodução por formas sociais coletivamente transmitidas". (GUSMÃO, 1999, 14). Ou seja, certas retóricas que adentram as instituições escolares sobre a diversidade são tratadas, em algumas ocasiões, com palavras suaves de eufemismo que tranquilizam as consciências ou produzem a ilusão de que assistimos a profundas mudanças.

$\mathrm{Na}$ educação escolar, trabalhar na perspectiva da diversidade cultural significa uma ação pedagógica que vai além de reconhecer que os alunos sentados nas cadeiras de uma sala de aula são diferentes. Por terem suas características individuais e ser pertencentes a um grupo social, é necessário promover uma pedagogia que valorize as diferenças. Isto só será possível mediante uma pedagogia que valorize a alteridade, como afirma Santos (2006).

A alteridade será possível somente "[...] num processo inverso ao da homogeneização proposta pelo campo político das relações entre povos e culturas distintas". Compreender o "outro" significa "[...] relativizar o próprio pensamento para construir um conhecimento que é outro". (GUSMÃO, 1999, p.16-17). 
Enfim, o processo de "ver-se" e "ver o outro" só pode ocorrer em contextos históricos concretos, seja em termos de senso comum ou em termos de conhecimento científico, o que leva a considerar, neste artigo, alteridade como a noção do outro, ou seja, o "eu" conhecer o "outro" que representa a diferença. Para perceber que a cultura passa inevitavelmente pelo conhecimento de outras culturas deve-se, portanto, reconhecer que o "eu" é uma identidade possível entre tantas outras, e não a única.

Para Louro (1999), a relação da diversidade e da diferença é um procedimento (des)construtivo das verdades estabelecidas socialmente, o que não elimina sua concepção hierárquica. Entretanto busca inseri-las nas relações de poder interpessoais e institucionais existentes, bem como não reproduzi-las de maneira inconsciente e ingênua. Dar voz aos diferentes grupos pode se transformar em um dos encaminhamentos possíveis da escola para repensar o sentido da diversidade.

Silva, (2001) salienta que essas pedagogias, por vezes contraditórias, constituem, exatamente, as instituições não escolares, que ensinam aos indivíduos o que podem e devem ser. Resultam da integração de conhecimentos científicos de um lado e, de outro, de crenças e valores de senso comum que são reproduzidos, transmitidos e aceitos conforme as relações de poder resultantes dos conflitos e negociações entre os indivíduos e as instâncias sociais.

No que concerne à escola, Silva (2001) recomenda uma abordagem curricular que trate a identidade e a diferença como uma questão política. Nesse sentido, distingue uma visão multicultural crítica e não crítica. De uma perspectiva não crítica, significa fortalecer a existência e a aceitação da diversidade de valores, crenças e identidades, enquanto de um posicionamento crítico, implica problematizar as identidades de gênero, raça e etnia relativamente à sua construção discursiva e, ao mesmo tempo, histórico-social.

\section{CONSIDERAÇÕES}

Por meio das discussões em pauta ressalta-se a necessidade de questionar o saber considerado hegemônico, as normas e condutas, duvidar do que foi e é 
afirmado como natural, questionar os comportamentos e as convicções préestabelecidos. Problematizar o currículo é um dos instrumentos para mobilizar alguns dos valores estabelecidos como norma social.

Por meio desses discursos, observa-se a necessidade de se abordar discussões sobre a diversidade cultural. Se colocadas em pauta pela escola, tais discussões podem contribuir para que o aluno reconheça de forma crítica as suas necessidades e desejos.

Embora com limitações, a instituição escolar pode favorecer a explicitação e tensões sobre raça, etnia, gênero, corpo e sexualidade que perpassam as relações de poder e de classe da sociedade. Dessa perspectiva, a escola pode colocar em questão os conhecimentos prévios - senso comum - que os indivíduos trazem de suas diferentes comunidades, tanto as já vivenciadas como as que estão vivenciando.

Nesse sentido, e com base nas referências consultadas, é possível afirmar que cabe à escola a tarefa de problematizar a "fabricação" das subjetividades, dos sentimentos, dos anseios e dos conflitos decorrentes das diferenças de gênero, raça, etnia e classe. A instituição escolar não apenas "produz" os indivíduos que a frequentam como é também produzida por eles e pelas representações e sentidos que nela circulam. Aos professores e professoras, cabe promover com os estudantes a oportunidade de compartilhar deste movimento.

\section{DELTON APARECIDO FELIPE}

Doutor e Mestre em Educação, Historiador I, professor do curso de História na Universidade do Estado do Paraná - Campus de Campo Mourão (Unespar/Campo Mourão.

\section{FABIANE FREIRE FRANÇA}

Doutora e Mestre em Educação, professora do curso de Pedagogia na Universidade do Estado do Paraná - Campus de Campo Mourão (Unespar/Campo Mourão).

\section{REFERÊNCIAS}

ABRAMOWICZ. Anete. Trabalhando a diferença na educação infantil. São Paulo: Moderna, 2006. 
APPLE, Michael W. Repensando ideologia e currículo. In: MOREIRA, Antonio Flavio Barbosa e SILVA, Tomaz Tadeu [et. al.] (orgs.). Currículo, cultura e sociedade. tradução de Maria Aparecida Baptista. 3. ed. São Paulo: Cortez, 1999.

ARAÚJO, Sônia M. da S. Cultura e educação: uma reflexão com base em Raymond Williams. ANPED, $2004 . \quad$ Disponível em:<www.anped.org.br/27/gt/03/t0315.pdf. $>$. Acesso: em 11/out/2008.

CANDAU, Maria Vera. Sociedade multicultural e educação: tensões e desafios. In CANDAU, Maria Vera (org.). Cultura(s) e educação: entre o crítico e pós-crítico. Rio de Janeiro: DP\&A, 2005.

COSTA, Marisa V. Mídia, magistério e política cultural. In: COSTA, Marisa V. Estudos Culturais em educação: mídia, arquitetura, brinquedo, biologia, literatura, cinema. Porto Alegre, Ed. Universidade/UFRGS, 2000.

FOUCAULT, Michel. A ordem do discurso. Aula inaugural no Collège de France, pronunciada em 2 de dezembro de 1970. Trad. Laura Fraga de Almeida Sampaio. São Paulo: Loyola, 2002. (1 ed. 1996, Série Leituras Filosóficas).

GIROUX, Henry. Praticando estudos culturais nas Faculdades de Educação. In: SILVA, Tomaz Tadeu da (Org.). Alienígenas na sala de aula: uma introdução aos estudos culturais em educação. Petrópolis: Vozes, 2003. p. 67-78.

GUSMÃO, N. M. M.. Linguagem, cultura e alteridade: imagens do outro. Cadernos de Pesquisa da Fundação Carlos Chagas. São Paulo/Campinas, v. 107, n. 0, p. 15-21, 1999.

HALL, Stuart. Da Diáspora: Identidades e mediações culturais. Belo Horizonte: UFMG, 2003.

HALL, Stuart. Quem precisa da identidade? In; SILVA, Tomaz Tadeu (org.). Identidade e diferença: a perspectiva dos Estudos culturais. Petrópolis-RJ: Editora Vozes; 2000.

LOURO. Guacira. L. Gênero, sexualidade e educação. Petrópolis: Vozes 1997.

SANTOS, Boaventura de Souza. A gramática do tempo: para uma nova cultura política. São Paulo: Cortez, 2006.

SILVA, Ana Célia da. Desconstruindo a Discriminação do Negro no Livro Didático - Salvador, BA, EDUFBA, 2005.

SILVA, Tomaz Tadeu. A produção social da identidade e da diferença. In; SILVA, Tomaz Tadeu (org.). Identidade e diferença: a perspectiva dos Estudos culturais. Petrópolis-RJ: Editora Vozes; 2000. 
SILVA, Tomaz Tadeu da. Documentos de Identidade: uma introdução às teorias do currículo. 2001. 2 ed. Belo Horizonte, Autêntica.

WOODWARD, Kathryn. Identidade e diferença: uma introdução teórica e conceitual In: SILVA, T. T. (Org.). Identidade e diferença: a perspectiva dos estudos culturais. 7. ed. Petrópolis, RJ: Vozes, 2007. p. 7-72. 